\title{
Modality in Lolita
}

\author{
Helen de Hoop and Sander Lestrade
}

\section{Introduction}

A remarkable property of language is that it allows people to talk about unreal events, and even to create wholly new worlds in narratives. ${ }^{1}$ But while the analysis of every-day language utterances of three or four words already constitutes a complex challenge to linguists, the structure and perception of narratives provide us with an even greater puzzle to be solved..$^{2}$ In this chapter, we will examine focalization and epistemic modality in a literary text, which reflect this cognitive feat. The literary work that we use for our study is Nabokov's novel Lolita (1955), with a retrospective (unreliable) first-person narrator, entailing double focalization. ${ }^{3}$

Epistemic modality in ordinary language is seen as relating to the speaker's degree of certainty about what the actual world is like. In literature, facts can be presented through the eyes of the characters, while being reported by the narrator. Moreover, this can be done more or less explicitly. Therefore, a literary text such as Lolita is an extremely interesting domain to look for the use and interpretation of epistemic modality. Whose degree of certainty is expressed when an epistemic modality marker is used, is it the narrator's (external focalization), or is it his past self's (internal focalization)? ${ }^{4}$ Maybe even more importantly, how do we know? Linguistic elements steer the understanding of a narrative text. Whereas research into such linguistic factors is undoubtedly relevant for literary studies, vice versa, the investigation of literary texts can give new insight in the mechanisms of language and communication. The language used by the writer or narrator already lifts the veil a little on their motives, underlying thoughts, strategies and their relation to their readers.

1 We thank our colleagues of the research group Grammar and Cognition and the interdisciplinary research group Narrativity, as well as the audience of the Conference on Text, Transmission, and Reception, held in Nijmegen at October 2010, for helpful comments and discussion. A special word of gratitude goes to Olaf Hoenselaar for his indispensable help in the first stage of the research reported here and to Claire Stocks for her editorial help in its final stage.

2 Cf. Dancygier (2012).

3 Cf. Rimmon-Kenan (2002).

4 Cf. Rimmon-Kenan (2002).

(C) HELEN DE HOOP AND SANDER LESTRADE, 2015 | DOI 10.1163/9789004270848_007

This is an open access chapter distributed under the terms of the Creative Commons AttributionNoncommercial 3.0 Unported (CC-BY-NC 3.0) License. 
One crucial characteristic that distinguishes human language from the language and communication means of other animals, is that it cannot only be used to describe the actual world, but also to go beyond this world. One example from the animal kingdom is the prairie dog. In order to warn each other about different species of predators, prairie dogs appear to have at their disposal different alarm calls which contain information about who these predators are, what they look like, and even what they are doing. Dependent on the exact type and degree of danger, different alarm calls trigger different types of (escape) behaviour among the other prairie dogs. ${ }^{5}$ We can interpret these alarm calls of prairie dogs as stating facts about the actual world, such as "There's a coyote!" or "There's a hawk flying around!" Being able to communicate such statements about the world certainly helps prairie dogs to survive in their extremely dangerous environment. At the same time, however, prairie dogs will presumably not be able to say things to each other like "There might be a coyote!" or "There must be a hawk flying around." These are utterances that do not state mere facts about the world but that can be conceived of as hypothesizing about it, to state what the world might or must be. By contrast, a major function of human language is indeed to hypothesize about what the actual world is like.

Modal expressions in language are used precisely for this purpose: to put forward hypotheses about what the world is like. As such, they weaken the factuality of the statement. ${ }^{6}$ Narrog defines modality in terms of factuality: "Modality is a linguistic category referring to the factual status of a state of affairs. The expression of a state of affairs is modalized if it is marked as being undetermined with respect to its factual status, i.e. is neither positively nor negatively factual."

Thus, if a speaker says "Joran is the murderer," then as far as they are concerned, that is a fact of the actual world. It is therefore presented as a fact, and will be interpreted as such by the hearer. This is not the case, however, when a speaker says "Joran might be the murderer," or "Joran must be the murderer." Although these two statements differ in strength (in the case of must she is more convinced that Joran is the murderer than in the case of might), in both cases she leaves open the possibility that Joran turns out not to be the murderer after all. Hence, the use of a modal expression indicates that the speaker does not present a certain fact about the world, but rather presents her hypothesis about the world.

5 Frederiksen and Slobodchikoff (2007).

6 Cf. Narrog (2005), Foolen and de Hoop (2009).

7 Narrog (2005) 184. 
Now, suppose the writer of a novel uses the sentence "Joran might be the murderer." Clearly, if the narrator is omniscient, then the epistemic modality of this expression might cannot be attributed to the narrator anymore, because an omniscient narrator would simply know whether Joran was the murderer or not in the fictive world. It might be, however, that the narrator is not (or pretends not to be) omniscient after all, and then the utterance is still interpreted as the narrator's hypothesis about the (fictive) world. Such a narrator's expression of uncertainty turns out to be very important for the reader's perception and appreciation of the narrative, as shown in an experiment by Dixon and colleagues. ${ }^{8}$ They conducted an experiment in which readers read a story (Emma Zunz by Jorge Luis Borges) twice. One group of readers read a manipulated version of the story, however, from which epistemic modality markers indicating uncertainty of the narrator, such as perhaps and might, were removed. This had a clear effect on the appreciation of the story by frequent but untrained readers. While the readers' appreciation of the original story significantly increased after rereading, this was not the case for readers of the manipulated story.

Epistemic modality markers do not necessarily express the uncertainty of the narrator, however. Another possibility is that the modal expression is interpreted with respect to the perspective of somebody else, that is, not the narrator, for instance one of the characters in the story. One of the questions we wish to answer in this chapter is whether, and if so how, we can interpret such a shift in perspective in case the character and the narrator refer to the same person in the fictive world. How do we know whether an expression of modality reflects the degree of certainty of the narrator or that of a character, especially when the narrator and the character are the same person?

In order to address this question, we will focus on the use of epistemic modality in the novel Lolita (1955) by Vladimir Nabokov. The first person narrator and main character of Lolita is Humbert Humbert, a man obsessed with his 12-year old stepdaughter. The story is a confession of an unreliable character and, therefore, is interesting to study in terms of the modality marking used by the narrator to reflect his own uncertainty either in his guise as distanced narrator looking back on events or as the main character narrating those events as they take place. Our aim is to analyze expressions of epistemic modality in the English novel in relation to (shifts in) narrative point of view. ${ }^{9}$ How does the narrator look back at the events? What was his role and how inevitable were some developments? The various levels of narration and the fluctuation in

8 Dixon et al. (1993).

9 Cf. Levie (2009). 
time that characterize Nabokov's Lolita make it an extremely rich source to look for interactions between modality and narrative point of view. For reasons of time and space, we will focus in this chapter on one specialized marker of epistemic modality, the auxiliary might.

\section{Modality in a Literary Text}

Notoriously, there are different types of modality found in language, which all involve the notions of possibility and necessity. ${ }^{10}$ For example, deontic modality involves external circumstances, which permit or oblige the participant to engage in the state of affairs. Two examples of deontic modality are given in (1) and (2), brought about by the use of the auxiliaries may and must respectively. Note that all examples in this chapter are taken from Lolita, published in the Penguin Books, 1995 (page numbers given after each example; boldface is ours):

(1) "She may meet boys at her own lovely home," I said. (p. 195)

(2) You must allow her to take part in The Hunted Enchanters. (p. 196)

Sentence (1) illustrates a case of deontic permission. The first person narrator and main character functions as an authority figure here, namely the father, who says that his daughter may meet boys at home. In sentence (2) we are dealing with a case of deontic necessity: this time the headmistress Pratt is the authority who insists that the father will allow the daughter to take part in a play. Narrog's factuality approach accounts for all types of modality, ${ }^{11}$ including deontic modality. In the above two sentences, the auxiliaries may and must make the statements less factual. That is, even though the father allows his daughter to meet boys at home, this does not entail that she actually meets or will meet boys (in fact, it's probably not even true that he would allow her, despite what he says). In (2), even though the headmistress insists that the father would allow his daughter to take part in the play, it is not certain that he will. Hence, both states of affairs in the scope of the modal auxiliaries are undetermined for their factual status.

As pointed out above, in a literary text the use of modality may vary with the person to whom the utterance is ascribed. Thus, modality can be expected to

10 Cf. Van der Auwera and Plungian (1998).

$11 \quad$ Narrog (2005). 
vary with the narrative point of view. Gavins, ${ }^{12}$ within the framework of Text World Theory, ${ }^{13}$ examines modalized propositions in literary fiction. Text World Theory is a theory at the interface between linguistic and literature study, and can be considered a linguistic theory dealing with the worlds created in literary fiction. Gavins focuses on those worlds which are created as a result of departing from the text-world initially established by a particular text, the so-called "sub-worlds." Sub-worlds can be constructed by discourse participants (and are thus "participant-accessible") or by characters within the textworld ("character-accessible"). Character-accessible sub-worlds are built upon epistemic modals in Text World Theory. Gavins notes that the text-world framework cannot provide a full picture of the important literary effects of modalization, such as pointed out by Simpson, ${ }^{14}$ because it has neglected a crucial element of literary narrative, namely focalization. According to Gavins, focalized narratives represent only what one character believes to be the case, and therefore constitute an epistemic modal world which is only characteraccessible.

However, Gavins does not discuss in detail how modal expressions are used to switch between worlds. What are the linguistic means that writers have at their disposal to make sure that the uncertainty expressed by the use of a modal auxiliary is attributed by the reader to the right person, be it the narrator or one of the characters?

As said above, Lolita is an interesting text to look at for the interaction of perspective and modality because it is a frame story in which the narrator and the main character are one and the same, and moreover are unreliable. This unreliability is particularly interesting for us if it affects the use of epistemic modality markers. It is on epistemic modality that we will focus for the remainder of this chapter, since it provides the most fruitful way of exploring the relationship between modality and narrative point of view or focalization. Epistemic modality is illustrated in the following example:

(3) There may have been times - there must have been times, if I know my Humbert - when (...). (p. 69-70)

The two modal auxiliaries in (3) are used to express the different degrees of certainty of the narrator himself. The narrator, looking back, could have uttered that there were times when... In that case, he would have presented his

\footnotetext{
12 Gavins (2005).

13 Werth (1999).

14 Simpson (1993).
} 
proposition as a fact of the actual (albeit fictive) world. Instead, he weakens the factuality of his proposition by stating that there may have been times when... (where may indicates epistemic possibility), and then, while gaining confidence, he corrects himself and adds that there must have been times (where must indicates epistemic necessity). From the linguistic context it is clear that we are invited to take the perspective of the narrator and not the main character Humbert here, also because in this example the auto-observant first person narrator Humbert refers to the character Humbert by the use of the third person proper name. Often, however, the character Humbert is referred to by the first person, just like the narrator Humbert, and it is an interesting question as to how the author deals with epistemic modality from the different perspectives: the perspective of the narrator I (Humbert) versus that of the character I (Humbert).

In principle, the first person narrator in Lolita can use epistemic modality in two situations. First, he can use it at a higher level, as in (3) above, taking a step back from the plot. Another example of this is given in (4):

(4) Perhaps, my learned readers may perk up if I tell them that even had we discovered a piece of sympathetic seaside somewhere, it would have come too late, since my real liberation had occurred much earlier: at the moment, in point of fact, when Annabel Haze, alias Dolores lee, alias Loleeta, had appeared to me, golden and brown, kneeling, looking up, on that shoddy veranda, in a kind of fictitious, dishonest, but eminently satisfactory seaside arrangement (although there was nothing but a secondrate lake in the neighbourhood). (p. 167)

By commenting on the hypothesized learned readers of his story, the narrator becomes a character himself at a higher level of narration (or: part of the world he is hypothesizing about). At this level, he uses the epistemic modal may in (4) above. The narrator is not certain of the fact that the readers will perk up, but hypothesizes that this may be the case.

Second, the narrator can use epistemic modality when representing the thoughts of a character, for example in direct speech. In that case, the modality expresses the lack of confidence of the character, not of the narrator himself. The character that the epistemic modality is attributed to can either be the character Humbert (who happens to be the same person as the narrator, but at a different time in the story), or any of the other characters. In (5) an example of the former is given, in (6) two examples of the latter. 
(5) I controlled my breath and said: "Dolores, this must stop right away. I am ready to yank you out of Beardsley and lock you up you know where, but this must stop. (...)" (p. 205)

(6) [Context: a letter from Lolita to Humbert] Pardon me for withholding our home address but you may still be mad at me, and Dick must not know. (p. 266)

In both (5) and (6) it is obvious that the modal expression (auxiliary) should not be taken to express the uncertainty of the narrator. Instead, it has to be attributed to a character. In (6) the modal expressions may and must are used by Lolita in a letter to Humbert, and therefore, it is clear that it is the character Lolita who weakens the factuality of the propositions she utters by using the modal auxiliaries. She considers the possibility that Humbert is still mad at her, and she insists that Dick, her husband, should not know. In (5) the effect of focalization is a little more complicated because the narrator and the main character Humbert are one and the same person, but because direct speech is used it is clear that it is the character Humbert (at that point in time) who expresses that "it must stop" right now. At that moment, it is not clear of course whether it will indeed stop, and therefore the modal auxiliary weakens the factuality of the statement of the character, who wants it to stop but who cannot be sure that it will actually stop. Thus we view this utterance from the perspective of the character Humbert. For the narrator would have known whether or not the action stopped, and so could have presented it as fact. The character Humbert, however, does not state that it stops, which would have been a fact of the fictive world at the time of utterance, but rather expresses his opinion that it should stop.

Both (5) and (6) thus linguistically encode the fact that the modal expression is not to be interpreted with regard to the narrator, but rather with regard to a character, Lolita in (6), and Humbert as a character in (5). The writer uses linguistic means by which the reader understands the modality in accordance with the perspective of somebody other than the narrator. The question is whether a writer actually needs to mark a shift in perspective linguistically, and if so, whether for each expression of modality in a literary text it has to be encoded to whom the modality is attributed. We will focus on the use of the epistemic modal auxiliary might in order to see whether and how the switch in focus between the narrator Humbert and the character Humbert is linguistically encoded. 


\section{Epistemic Might and Perspective in Lolita}

The auxiliary might in English is rather special as it has the epistemic modal reading as its basic, canonical reading. Usually, modal auxiliaries have other modal readings as their basic reading, such as the deontic modal reading for must and the participant-internal modal reading for can. ${ }^{15}$ By contrast, the auxiliary might is specialized for epistemic modality readings, just like epistemic modal adverbs such as perhaps and probably are, and therefore this auxiliary is particularly useful for a study of the encoding of perspective shifts in the interpretation of epistemic modality. Consider an example on the use of the epistemic modal auxiliary might in Lolita:

(7) I tipped the chauffeur and hoped he would immediately drive away so that I might double back unnoticed to my hotel and bag; but the man merely crossed to the other side of the street where an old lady was calling to him from her porch. (p. 36)

The modal expression in (7) is syntactically embedded under the verb hoped and thereby expresses the hope of the character Humbert instead of that of the narrator Humbert. It may not always be so clear which perspective is taken. One potentially ambiguous case is illustrated in (8).

(8) No Miss Opposite sat on the vined porch - where to the lone pedestrian's annoyance two pony-tailed young women in identical polka-dotted pinafores stopped doing whatever they were doing to stare at him: she was long dead, no doubt, these might be her twin nieces from Philadelphia. (p. 287)

In principle, it could be either the narrator or the character Humbert in (8) who speculates about the women on the porch. Either the narrator Humbert, looking back at the course of the events, supposes that the two girls he saw right then could have been Miss Opposite's twin nieces from Philadelphia, or the character Humbert at that point in time, seeing the two young women thought that they could be. But do readers know, and if so how do they know, to whom to attribute the modal expression in cases like these?

In the following fragment, we observe a shift in perspective (from the first person narrator Humbert to the first person character Humbert) with a con-

15 Cf. Foolen and de Hoop (2009), van Gerrevink and de Hoop (2011). 
comitant shift in the scope of the epistemic modality expression might. How does this shift come about?

(9) One might suppose that with all blocks removed and a prospect of delirious and unlimited delights before me, I would have mentally sunk back, heaving a sigh of delicious relief. (...) Instead of basking in the beams of smiling Chance, I was obsessed by all sorts of ethical doubts and fears. For instance: might it not surprise people that Lo was so consistently debarred from attending festive and funeral functions in her immediate family? (p. 105)

In the first sentence, the narrator addresses the reader indirectly ("one") and the first instance of might is clearly interpreted from the perspective of the narrator, hence it provides a broad overview of the complete story. In order to attribute the second instance of might to the perspective of the first person character Humbert rather than to the first person narrator Humbert, the modal expression is embedded in the thoughts and feelings of the character (as in (in)direct speech). In the fragment above, the narrator states that the first person character is obsessed by all sorts of ethical doubts and fears. Then what follows is an example of these doubts and fears: "For instance:". Hence, we interpret the modal expression in the scope of these doubts and fears, i.e. from the perspective of the character Humbert.

Below is another example of might attributed to the narrator again:

(10) As the ass I was I had not memorized it. What remained of it in my mind were the initial letter and the closing figure as if the whole amphitheatre of six signs receded concavely behind a tinted glass too opaque to allow the central series to be deciphered, but just translucent enough to make out its extreme edges - a capital P and a 6. I have to go into those details (which in themselves can interest only a professional psychologue) because otherwise the reader (ah, if I could visualize him as a blondbearded scholar with rosy lips sucking la pomme de sa canne as he quaffs my manuscript!) might not understand the quality of the shock I experienced upon noticing that the $\mathrm{P}$ had acquired the bustle of a $\mathrm{B}$ and that the 6 had been deleted altogether. (p. 226)

In this example the shift in tense - from past tense ("the shock I experienced") to represent the perspective of the character Humbert to present tense ("I have to go into those details") for the perspective of the narrator Humbert - indicates that might is used to express the narrator's uncertainty about the truth of 
the proposition: it might be true that the reader presently does not understand the quality of the shock that the character Humbert experienced in the past. Of course, reference to the reader itself also indicates that the narrator Humbert's perspective is taken, even independently of the grammatical tense, as the character Humbert does not know of any reader.

\section{Methodology}

Rather than speculating further about when and how readers know to shift their focus from the narrator to the character Humbert in interpreting expressions of (epistemic) modality, we decided to investigate the question more systematically. To that end, we withdrew all contexts from Lolita in which the modal expressions may, might, or must are used. This yielded 271 contexts in total ( 83 mays, 136 mights, and $5^{2}$ musts). We annotated this set for type of modality and for perspective taken. In principle, each author took care of half of the instances, but we annotated 57 doubles to check if our annotation was consistent. We agreed on $95 \%$ ( 54 items; mismatches were solved through discussion). With each category occurring more or less equally often ( 26 vs. 28 in our test set), we do not have to compute the kappa score to correct for expected overlap but can simply assume that the inter-annotator agreement score with this percentage of agreement is very good. That is, we can be confident about our classification of perspective. Within this set, we then focused on the epistemic uses of might that could be attributed to either Humbert the character or Humbert the writer. Next, we carefully examined the linguistic encoding of either version.

\section{Results}

We found that the interpretation of epistemic modality from the perspective of the character Humbert arises when explicit linguistic embedding is offered. Otherwise, the (default) interpretation of might is epistemic modality from the perspective of the narrator. So, in (11) both instantiations of might are related to the perspective of the character Humbert, and twice this is linguistically encoded.

(11) It occurred to me that if I were really losing my mind, I might end by murdering somebody. In fact - said high-and-dry Humbert to floundering Humbert - it might be quite clever to prepare things - to transfer the 
weapon from box to pocket - so as to be ready to take advantage of the spell of insanity when it does come. (p. 229)

Note that (11) is a very clear example of epistemic modality attributed to the character Humbert, and this use is clearly encoded. The first occurrence of might is subordinate to the matrix clause "It occurred to me" which guarantees the correct perspective for the interpretation of might here, that is the perspective of the character Humbert. The second occurrence of might is even more explicitly marked as such, since it is presented as reported speech "said highand-dry Humbert to floundering Humbert." Here the character tells himself that it might be a good idea to prepare things. Another example is given in (12):

(12) A happy thought struck me. If and when master returned from his constitutional in the woods, or emerged from some secret lair, it might be wise for an unsteady gunman with a long job before him to prevent his playmate from locking himself up in a room. (p. 294)

Again, in (12) the epistemic modal might is clearly presented as part of the thoughts of the character Humbert by the overt explicit reference to his thoughts ("A happy thought struck me"). Three last examples of the explicit linguistic marking of the shift in perspective to the character Humbert, are presented in (13)-(15):

(13) I wondered idly if some surgeon of genius might not alter his own career, and perhaps the whole destiny of mankind, by reviving quilted Quilty, Clare Obscure. (p. 306)

(14) The road now stretched across open country, and it occurred to me - not by way of protest, not as a symbol, or anything like that, but merely as a novel experience - that since I had disregarded all laws of humanity, I might as well disregard the rules of traffic. (p. 306)

(15) Then, figuratively speaking, I shattered the glass, and boldly imagined (for I was drunk on those visions by then and underrated the gentleness of my nature) how eventually I might blackmail - no, that is too strong a word - mauvemail big Haze into letting me consort with little Haze by gently threatening the poor doting Big Dove with desertion if she tried to bar me from playing with my legal stepdaughter. (p. 71) 
In (13) might is in the scope of the matrix clause "I wondered," thus expressing the character Humbert's thoughts. In the above cases the epistemic modality is used by the narrator to indirectly represent the ideas of his characters. Obviously, the narrator must make sufficiently clear to the reader whose thoughts are expressed, his or the ones of his character. Mostly, this is done by explicitly embedding the modal expression under mental verbs, such as "it occurred to me" in (14) and "I imagined" in (15).

When the narrator of Lolita uses epistemic modality at a higher level of narration, that is, when becoming a character himself, this can also be marked in various ways of which we already have shown some examples above. Lolita is a frame story. The narrator is a character in the story, but he is also a character at a higher level at which he is writing his confession in prison. There are various ways in which the narrator can go to this higher level. For example, he can mention or address his readership, the members of the jury of his (future) trial for murder. In (16), an example with the modal expression might is given:

(16) Then I pulled out my automatic - I mean, this is the kind of fool thing a reader might suppose I did. (p. 278)

In addition to addressing his readership, the narrator in (16) is playing with the plot (that is, he did not really put out his gun) and uses punctuation, i.e., the hyphen, to mark the switch to the higher level. Just as a character does not know about readers, so he/she does not know about the writing process. Therefore, if the narrator is commenting on the writing process, we know that we are at the higher plot level again. One important example that illustrates this process effectively is given below. The excerpt does not contain the epistemic modal auxiliary might, but some other modal expressions (in boldface) are interpreted with respect to the perspective of the narrator:

(17) And now take down the following important remark: the artist in me has been given the upper hand over the gentleman. It is with a great effort of will that in this memoir I have managed to tune my style to the tone of the journal that I kept when Mrs Haze was to me but an obstacle. That journal of mine is no more; but I have considered it my artistic duty to preserve its intonations no matter how false and brutal they may seem to me now. Fortunately, my story has reached a point where I can cease insulting poor Charlotte for the sake of retrospective verisimilitude. (p. 71) 
The auto-observant first person narrator reveals here that in his report of the course of the events he had tried to be faithful to the perspective of the first person character that he was in those days (when he kept a journal that he later lost). Now, at this point in the story, he no longer feels the need to do so. From that moment on, the narrator allows the reader to feel empathy with Charlotte, and the narrator pretends he feels empathy as well, indicated by the use of the attributive adjective "poor" for Charlotte, but also by the use of the modal expressions: he "managed" to tune his style as if Charlotte was still but an obstacle to him ("managed" implicates that it was not easy to do so), although this tone "may" seem "false and brutal" to him now, and he is relieved (indicated by the evaluative adverb "fortunately") when he "can" stop insulting "poor Charlotte."

Another way of leaving the lower plot to get to a higher level perspective is by the use of punctuation, for example brackets or parentheses. A good example is given in (18):

(18) Bourbon Street (in a town named New Orleans) whose sidewalks, said the tour book, "may [I liked the "may"] feature entertainment by pickaninnies who will [I liked the "will" even better] tap-dance for pennies" (what fun), while "its numerous small and intimate night clubs are thronged with visitors" (naughty). (p. 156)

In (18), the modal auxiliary may is in a quotation from a tour book, whence the modality is attributed to the author of the tour book, but within the quote the part between brackets is to be interpreted at a higher level, in this case the level of the first person character Humbert (indicated by the past tense).

An example where modal might is interpreted at the level of the character Humbert but commented upon by the narrator, is given in (19):

(19) "For the benefit of Leslie and Louise who might (and did) report it to John and Jean I made a tremendously loud and beautifully enacted longdistance call and simulated a conversation with Shirley Holmes." (p. 100)

By the addition of "and did" in parentheses, we know that what was thought to be possible must have been in the mind of the character; the narrator knows, and states, that this was actually true indeed. Note that the interpretation of might in (19) as being in the scope of the character Humbert would not have been so clear without the addition of "(and did)." Without the added comment of the narrator on what really happened, might might (and would?) have been interpreted as expressing possibility from the perspective of the narrator (in 
that case he would not have known whether Leslie and Louise had actually reported the call to John and Jean). By marking the narrator's perspective explicitly, we infer that the preceding modal expression should be attributed to the character.

Consider (20) as an example where might expresses the possibility considered by the narrator:

(20) All at once we were madly, clumsily, shamelessly, agonizingly in love with each other; hopelessly, I should add, because that frenzy of mutual possession might have been assuaged only by our actually imbibing and assimilating every particle of each other's soul and flesh; but there we were unable even to mate as slum children would have so easily found an opportunity to do. (p. 12)

The shift in perspective from the character to the narrator is already initiated here by the "hopelessly, I should add," which makes the transition to the narrator's perspective for the interpretation of might an easy one. However, even without such evident clues, it seems possible to shift to the narrator's perspective in the interpretation of modal might. This is shown in (21), for example:

(21) This time I hit something hard. I hit the back of a black rocking chair, not unlike Dolly Schiller's - my bullet hit the inside surface of its back whereupon it immediately went into a rocking act, so fast and with such zest that any one coming into the room might have been flabbergasted by the double miracle: that chair rocking in a panic all by itself, and the armchair, where my purple target had just been, now void of all live content. (p. 302)

Although (21) represents a clear example of a focalized narrative, accessible for the reader through the eyes of the character Humbert, the modal expression might is interpreted with respect to the perspective of the narrator Humbert. Hence, might triggers a shift in perspective that is not marked by any linguistic means. We have seen that when might is to be interpreted with respect to a character's perspective, it is in the vast majority of cases explicitly encoded as being in the scope of the character's thoughts. In the example in (21) above, this interpretation could have been achieved by adding a matrix mental verb, such as for example: "It occurred to me that any one coming into the room might have been flabbergasted (...)." However, it seems that the lack of such overt marking of an embedded perspective automatically gives rise to the interpretation where the epistemic modality is attributed to the narrator, even in 
a focalized narrative context. In other words, if the narrator wants the reader to interpret a modal expression as the expression of his own uncertainty, he does not have to mark this explicitly, as it is the default interpretation of the modal that automatically arises in the absence of explicit marking to the contrary.

One interesting example of focalization where one would not expect it to be necessary to mark explicitly the change to the perspective of the character, is in a diary context that is entirely attributed to the character Humbert. Consider the following entry:

(22) Saturday. (Beginning perhaps amended.) I know it is madness to keep this journal but it gives me a strange thrill to do so; and only a loving wife could decipher my microscopic script. Let me state with a sob that today my L. was sun-bathing on the so-called "piazza," but her mother and some other woman were around all the time. Of course, I might have sat there in the rocker and pretended to read. (p. 42)

Clearly, no extra explicit marking is necessary for the might to be attributed to the character Humbert, but this is because in the diary, the character Humbert has become the (lower level) narrator of the story. Generally, the reader of a diary will assume no change of perspective without explicit cues (e.g. "This was the diary, now our story continues"). Yet, note that the higher level narrator of Lolita plays with this assumption. In the following example, we have apparently made the switch to the higher level narrator's perspective somewhere, as we are explicitly told to resume the diary again. It seems that only after this explicit marking, might is again attributed to the lower level narrator of the diary, i.e., the character Humbert.

(23) A poet à mes heures, I composed a madrigal to the soot-black lashes of her pale-gray vacant eyes, to the five asymmetrical freckles of her bobbed nose, to the blonde down of her brown limbs; but I tore it up and cannot recall it today. Only in the tritest of terms (diary resumed) can I describe Lo's features: I might say her hair is auburn, and her lips as red as licked red candy, the lower one prettily plump - oh, that I were a lady writer who could have her pose naked in a naked light! (p. 44)

In fact, the diary, which is not the "original" one, but which is reconstructed by the higher level narrator, is full of such perspective switches. For example, the narrator suddenly says in the middle of what seemed to be a diary entry: 
(24) All at once I knew I could kiss her throat or the wick of her mouth with perfect impunity. I knew she would let me do so, and even close her eyes as Hollywood teaches. A double vanilla with hot fudge - hardly more unusual than that. I cannot tell my learned reader (whose eyebrows, I suspect, have by now travelled all the way to the back of his bald head), I cannot tell him how the knowledge came to me; (...). (p. 48)

Obviously, there is no "learned reader" for the writer of the diary. Again, we must have taken the narrator's perspective instead of that of the character at some point. Importantly, these interventions make the perspective of the whole diary section questionable. Contextual embedding therefore is a less reliable determinant for the perspective than syntactic embedding.

In sum, we have shown that for the interpretation of modal expressions all changes of perspective from the narrator to a character (or to a lower level narrator) are marked by either syntactic or contextual embedding. Epistemic modal expressions that are not explicitly assigned to a character seem to be attributed to the narrator by default.

\section{Conclusion}

A narrator who is omniscient is not expected to be unsure about the world he is inventing himself. In this paper, we have studied the use of the epistemic modality auxiliary might in Nabokov's Lolita in two situations: (i) when the narrator becomes a character at a higher level of a frame story; (ii) when he represents the perspective of one of his characters. The different levels of the frame story can be made explicit in various ways. The narrator can address his readership, comment on the writing process, or use punctuation to mark a switch of frame. When a modal expression is interpreted with respect to one of the character's perspectives, this is almost exclusively marked by syntactic embedding. This finding can be accounted for as follows. Epistemic modality in every-day communication expresses a speaker's hypothesis about the actual world. In a narrative the narrator is the speaker and the world is the fictive world. Hence, epistemic modality is by default attributed to the narrator, being the speaker of the literary text. If an epistemic modal expression is to be interpreted from the perspective of one of the characters, however, this must be explicitly encoded as such. 


\section{References}

\section{Primary Source}

Vladimir Nabokov, Lolita (1955). Published in Penguin Books 1995, London.

\section{Secondary Sources}

van der Auwera, J. and V. Plungian, "Modality's semantic map," in Linguistic Typology 2 (1998), pp. 79-124.

Dancygier, B., The Language of Stories (Cambridge, 2012).

Dixon, P., M. Bortolussi, L.C. Twilley and A. Leung, "Literary processing and interpretation: Towards empirical foundations," in Poetics 23 (1993), pp. 5-33.

Foolen, A. and H. de Hoop, "Conflicting constraints on the interpretation of modal auxiliaries," in Cross-linguistic Semantics of Tense, Aspect, and Modality, eds. L. Hogeweg, H. de Hoop and A. Malchukov (Amsterdam, 2009), pp. 303-16.

Frederiksen, J.K. and C.N. Slobodchikoff, "Referential specificity in the alarm calls of the black-tailed prairie dog," in Ethology, Ecology \& Evolution 19 (2007), pp. 87-99.

Gavins, J., “(Re)thinking modality: A text-world perspective," in Journal of Literary Semantics 34 (2005), pp. 79-93.

van Gerrevink, R. and H. de Hoop, "On the interaction of tense, aspect and modality in Dutch," in Bidirectional Optimality Theory, eds. A. Benz and J. Mattausch (Amsterdam, 2011), pp. 151-68.

Levie, S.A., "Exile and Assimilation. Some Notes on Vladimir Nabokov's Journey through Space and Time," in Arcadia 44 (2009), pp. 401-20.

Narrog, H., "On defining modality again," in Language Sciences 27(2) (2005), pp. 165-92.

Rimmon-Kenan, S., Narrative Fiction, 2nd ed. (London and New York, 2002).

Simpson, P., Language, Ideology and Point of View (London, 1993).

Werth, P., Text Worlds: Representing Conceptual Space in Discourse (London, 1999). 